\title{
A Review of Early Sport Specialization in Relation to the Development of a Young Athlete
}

\author{
Jonathan Michael Normand \\ Educational Leadership \& Policy Studies, Tarleton State University, Box T-0210, Stephenville, Texas, 76401, USA \\ E-mail: jonathan.normand@sville.us \\ Andrew Wolfe \\ Kinesiology Department, Tarleton State University, Box T-0370, Stephenville, Texas 76401, USA \\ E-mail: awolfe@tarleton.edu \\ Kayla Peak (Corresponding author) \\ Kinesiology Department, Tarleton State University, Box T-0370, Stephenville, Texas 76401, USA \\ E-mail: peak@tarleton.edu
}

Received: 04-03- 2017

Accepted: 20-04- 2017

Published: 30-04- 2017

doi:10.7575/aiac.ijkss.v.5n.2p.37

URL: http://dx.doi.org/10.7575/aiac.ijkss.v.5n.2p.37

\begin{abstract}
Background: The overall physical and psychological development of a young athlete is crucial for the enjoyment of physical activity for a lifetime. Children, as well as parents, tend to focus on individual accomplishment in sport despite any other aspect of physical development or appropriate training. Objective: the pressure to excel in sport has all too often brought about negative consequences through specialization at an early age. Method: A review and commentary report on the impact of early sport specialization on the physical and psychological development of a young athlete. Conclusion: A long-term, activity and age-appropriate developmental model is essential to those involved in training young athletes. Sport specialization may be appropriate in unique situations but only after the development of specific skills, abilities, and psychological maturity. As sport professionals, parents and coaches should be educated the $\mathrm{pros} / \mathrm{cons}$ of early sport specialization. Ultimately, the focus on sport participation should be to increase physical activity, psychological development, and appreciation for a lifetime.
\end{abstract}

Keywords: Early Sport Specialization, Sports, Youth Sports, Youth Athletics

\section{Introduction}

Society recognizes exceptional individual performances, especially in sport (Ericsson, Krampe, \& Tesch-Römer, 1993). Pressure coming from parents, coaches, and the young athletes themselves create a strong desire to focus on one sport from a very young age (Gould, 2010). Of the estimated 45 million youth and adolescents participating in sport, early specialization continues to be a popular choice despite concerns (Merkel, 2013). Early sport specialization is an intense, year-round training program in a single sport at the exclusion of other activities (Ferguson \& Stern, 2014). Youth are persuaded to choose a sport early in order to quickly improve skills for a chance to be recognized as an elite performer (Ferguson \& Stern, 2014). Increased recruiting exposure with college coaches is often identified as one of the primary reasons for year-round focus on one sport (Korman, 2015). Youth sports have a unique influence on healthy behavior and development, yet the psychological, social, and physical risks of specializing in a particular sport may inhibit healthy physiological and psychological growth (Russell \& Limle, 2013). Both parents and coaches should be concerned about the importance of periodization in long-term age-appropriate training with an emphasis on physical and psychological developmental factors (Bailey et al., 2010). Prior research on early sport specialization has sought to determine advantages and disadvantages of choosing one sport at the expense of being a multi-sport participant (Ferguson \& Stern, 2014). Ericsson et al. (1993) stated 'that it takes 10,000 hours (20 hours for 50 weeks a year for ten years)' of concentrated, deliberate practice to become an expert performer in an activity. However, this is not an indicator of transformation into an elite athlete, which requires a diverse set of skills and physical development (Martindale, Collins, \& Daubney, 2005). The 10,000 hour research study made its way into 'the sports training world with the belief that early acquisition of training hours' at a young age will lead to greater success (Ericsson et al., 1993; Ferguson \& Stern, 2014). The concept directly influenced early sport specialization without accurately identifying potential risks (Wiersma, 2000). A program requiring high-volume, intense, one-dimensional training at a young age, without a variety of appropriate activities, can prove detrimental to the individual (Ferguson \& Stern, 2014). The logic of promoting early sport specialization is questionable since $98 \%$ of young athletes will never reach elite status (Wiersma, 2000). Young athletes who focus on a single sport are making a year-round decision that will either positively or negatively affect physiological and psychological development for a lifetime. The purpose of this article is 
to provide a better understanding of the benefits and drawbacks of year-round training in youth sports so that parents and coaches can make intentional, educated decisions about sport specialization at an early age.

\section{Influencing Factors of Youth Single Sport Specialization}

Researchers have noted various reasons young athletes make the decision to specialize in a particular sport. Ericsson et al. (1993) introduced a significant study indicating how modern society recognizes exceptional performances, especially in sports, arts, and science. Specifically, the researchers claimed that expert performers commit full-time to a specific area of performance which takes 10,000 hours of deliberate practice (Ericsson et al., 1993). This particular study made its way into the athletic performance world with the belief that early acquisition of dedicated, thoughtful practice will lead to greater success. However, this is not necessarily indicative of a conversion into an elite athlete, which requires a varied set of skills and development (Ferguson \& Stern, 2014; Gould, 2010; Martindale et al., 2005). In addition, Bailey et al. (2010) noted that physical talent alone is unlikely to lead to successful participation due to an array of supplemental factors (social, physical, technical, and psychological). Research reveals reasons young athletes are prompted toward early sport specialization including better coaching for more talented players, fear of falling behind the competition, parental expectations, pressure from coaches and college recruiters, and an athlete's desire to participate in championship-caliber games (Gould, 2010).

\subsection{Benefits of Early Sport Specialization}

Research has shown positive aspects of early specialization on the development of a young athlete. Gould (2010) recorded that specialized athletes receive better coaching and skill instruction, heightened skill acquisition through deliberate practice, improved time management skills, productive use of structured time, enjoyment of talent development in sport, and diverse peer relationships. Additional benefits, such as the potential for increased recognition, attainment of professional status, a college scholarship, or an Olympic qualification lead many athletes and coaches to believe that it is foolish not to specialize (Wiersma, 2000). A prime example supporting the advocates of early sport specialization can be found in the incredible career of Tiger Woods. An accomplished golfer, Tiger recorded his first round of 70 on a regulation course at age 12. According to Callahan (2010), Earl Woods, Tiger's father, was hyperfocused on building a champion golfer. Intense practice schedules and mental toughness training provided the foundation for Tiger's success on the links. Ferguson and Stern (2014), found that many parents, and young athletes, select sport specialization to gain a competitive edge, to master skills faster, early talent recognition, and an increased opportunity for scholarships or professional contracts. Obviously, the early specialization and myopic dedication paid off for Tiger Woods.

\subsection{Disadvantages of Early Sport Specialization}

Sports scientists are worried that young athletes specialize too early leading to overuse injuries, loss of motivation, and emotional exhaustion. Also, the costs and time demands of the commitment to specializing in a sport do not justify results in which a slight percentage become elite athletes (Gould, 2010). Wiersma (2000) added that elite athletes represent a small minority of the participants in the United States; therefore, early sport specialization may prove illogical. Rigorous hours of intense training through specialization may interfere with the benefits of sport participation causing young athletes to develop poor self-concept and social skills, impair relationship building, and missed educational opportunities (Ferguson \& Stern, 2014; Russell \& Limle, 2013; Wiersma, 2000). DiFiori et al. (2014) noted that early sport specialization may result in overuse injury resulting in demotion from the active player roster and possibly threaten future sport participation. Research also reveals psychological concerns regarding athlete burnout and unrealistic parent expectations. The stringent demands of training may become excessive in which the athlete may withdraw from the activity. Excessive parent involvement elevates anxiety, decreases enjoyment, and lowers enthusiasm and self-determination for the young participant (Ferguson \& Stern, 2014; Russell \& Limle, 2013; Wiersma, 2000). Russell and Limle (2013) reported that recent trends reveal that organized youth sport is replacing self-organized physical play resulting in less opportunity for young people to be active and enjoy the sport on their own.

The physical development of a young athlete remains a primary concern in sport participation. Russell and Limle (2013) claimed that specialization might inhibit or distort proper physical development, limit motor development, and decrease involvement in activities that promote lifelong fitness and well-being. The acquirement of cross-sport skills ensuring youth's enjoyment of sport are keys to participation for the rest of a young athlete's life (Ferguson \& Stern, 2014). Year-round participation in one sport often leads to overuse, overtraining, and injury to an athlete, thereby limiting overall growth and physical development. Myer et al. (2015) argued that the "increased degree of specialization is positively correlated with increased serious overuse injury risk" (p. 441). Proper rest within an intense training regimen is essential for both physical and mental recovery, yet rest periods are frequently overlooked (Ferguson $\&$ Stern, 2014; Gould, 2010; Russell \& Limle, 2013; Wiersma, 2000). Merkel (2013) reported an "increase in sportsrelated injuries, a $70-80 \%$ attrition rate by the time a child is 15 years old, and an over-emphasis on winning are problems encountered in youth sport" (p. 151).

\section{Multi-sport Participation Opposed to Specialization}

The relationship between sport specialization and multiple-sport participation to the overall development of a young athlete is an important topic of discussion. Multi-sport participation, sampled at a young age, is linked to a longer career in sport and provides for a range of experiences through different coaches to maximize physiological as well as healthy psychological development (Gould, 2010; Russell \& Limle, 2013). In addition, participation in multiple youth sports allows for periods of active rest and recuperation. Experts recommend that young athletes should have a 
minimum of one to four off-weeks per year, with additional periodic off-weeks integrated between phases or sport seasons (Haff \& Triplett, 2015). These off-weeks provide time for injury recovery and burnout prevention, yet offweeks may not occur in single sport specialization (Haff \& Triplett, 2015). Sport should be used to advance a young athlete's sense of autonomy, which is seen to occur in multi-sport participation versus a highly organized and controlled setting in specialization (McLeod et al., 2011; Russell \& Limle, 2013). Ferguson and Stern (2014) added the importance of sampling sports to develop a variety of motor skills, maintain interest, and focus on keeping sport fun to promote a higher likelihood of adult participation and physical activity. Multi-sport participation facilitates positive physical development of youth. The skeptical parent or athlete concerned with multi-sport involvement delaying the acquisition of 10,000 hours should consider and recognize the exceptional benefits associated with transferable skills (Ericsson et al., 1993). For example, expert soccer player's knowledge of American football might be limited, but transferred skills acquired through soccer participation allows for a successful transition and quality performance as a punter or kicker. A similar perceivable transfer scenario may involve overhead throwing sports such as baseball, cricket, football, or softball. Baker, Cote, and Abernethy (2010) examined the historical characteristics associated with expert team sport players. The study identified a significant negative correlation between the number of external activity participation and total hours associated with sports specialization prior to achievement of expert-level play, thus suggesting multi-sport participation is a fundamental component of expert development (Baker et al., 2010). While precise movement patterns and mechanics differ across sports, skill proficiency is dependent on previous skill acquisition, regardless of the activity or sport. Therefore, while the athlete participates in an off-season or secondary sport/activity, the acquired skills and knowledge possess transfer values which significantly influence and contribute to the enhancement of skills and knowledge for the primary sport of interest.

\subsection{Physical Development of Young Athletes}

Previously reported research stressed the importance of integrating periodization, rest, and recovering into program design to reduce overuse injuries and burnout potential (Haff \& Triplett, 2015). Research also indicates that individuals undergo a non-linear developmental process regarding anatomical, neurological, muscular, and hormonal changes. This variance affects the rates of physical development for each person (Bailey et al., 2010; DiFiori et al., 2014). Therefore, an individual's rate of improvement and timing of peak performance in sport varies (Bailey et al., 2010; DiFiori et al., 2014). Merkel (2013) noted that sport participation could promote a positive impact on youth regarding physical activity, enhanced fitness, lifelong benefits, decreased risk of obesity and chronic disease, and motor skill improvement. However, untrained youth coaches with alternative priorities often contribute to overuse injury, inconsistent safety standards, and an overall lack of sports science influencing policy and practices (DiFiori et al., 2014; Merkel, 2013). Multi-sport participation facilitates positive physical development of young athletes.

\subsection{Psychological Development of Young Athletes}

Research suggests that proper psychological growth of a young participant through sport has a lasting impact. The development of psycho-behavioral skills enables an individual to realize their potential and make cognitive choices across a lifespan (Bailey et al., 2010). These particular skills play a crucial role in maintaining self-motivation to continue sport participation (Bailey et al., 2010). A systematic process of setting, developing, and reviewing goals is crucial to assist an athlete throughout development. Goals provide integrated direction and purpose for the development of intrinsic motivation. Also, the development of an athlete's ability to handle stress while balancing life and sport develops a healthy mental state that can aid in burnout prevention (Martindale et al., 2005). Merkel (2013) noted sport participation could promote a positive impact on healthy psychological development through decreasing depression and high-risk behaviors, increased positive behavior with peers, and improved self-concept. Early sport specialization participation may have an adverse psychological impact on increased stress to become an elite player which can lead to high rates of attrition, over-emphasis on winning, and inappropriate expectations (Merkel, 2013).

\section{Youth Developmental Guidelines and Considerations}

Sport participation standards and parental education concerning healthy and enjoyable youth sport experiences for young athletes should be emphasized within youth sport organizations. DiFiori et al. (2014) expressed that parents and coaches need to be educated regarding a young athlete's sport readiness related to appropriate cognitive and motor skill development. Deliberate practice is a significant aspect of developing a range of motor and cognitive experiences that youth can bring to a sport. This intentional practice enables a young athlete to create and experiment with activities on their own and with friends to enhance intrinsic motivation, immediate gratification, and maximize enjoyment rather than focusing specifically on performance improvement (Gould, 2010; Strachan et al., 2009). Research stresses longterm age appropriate training should emphasize periodization, in which rest from physical activities are pre-planned to emphasize proper physical and psychological development (Bailey, Collins, Ford, MacNamara, Toms, \& Pierce, 2010; McLeod et al., 2011). An emphasis on appropriate development, as opposed to early success, includes less emphasis on winning at developmental stages, clear expectations at every level with the big picture of development as the focus, and provide specific experiences and teachings to be integrated into youth sport. A coach reward system may be a logical solution to reinforcing these standards by providing direction and attitude for long-term development (Martindale et al., 2005). Merkel (2013) suggested a need to change the philosophy of youth sport with an emphasis on fun while establishing physical fitness, psychologic well-being, and lifelong lessons. This positive change will only be effective through a collaborative effort between parents, coaches, teachers, health professionals, community leaders, and even politicians. Strachan et al. (2009) researched eight features in youth structured programs to encourage a positive outcome such as physical and psychological safety, appropriate structure, supportive relationships, opportunities to 
belong, positive social norms, support of efficacy, skill building opportunities, and an integration of family, school, and community. Since early sport participation is a traditional route, the recognition of age and health appropriate programs are vital to properly educate youth athletes, parents, and coaches (Ferguson \& Stern, 2014). Research has revealed key elements of a long-term model should include a pre-participation physical examination to identify potential risk factors in addition to consistent surveillance to assist in the prevention and treatment of possible overuse injury (Thompson, Arena, Riebe, \& Pescatello, 2013). From a medical perspective due to increased injury, the total amount of constant activity needs modification with intent to diversify training procedures and allow for recovery time. Appropriate training and conditioning programs should include preseason and in-season preventative fitness training, scheduling 1-2 days off per week, progressive training intensity each week, and applying appropriate recovery time following injury (McLeod et al., 2011). The difficult choice many youth and parents face at some point in a sports career is whether or not to specialize in a single sport or participate in multiple sports. However, there are many components related to this decision that ultimately have an impact on the overall health of the individual. Ferguson and Stern (2014) concluded that sport specialization might be necessary for those in search of becoming an elite athlete, yet appropriate timing and training is vital for long-term success. The major objective, from a medical standpoint, is to convey knowledge to those involved in this decision regarding risk factors and proven steps in the prevention of occurrence of both physical and psychological injury (DiFiori et al., 2014; McLeod et al., 2011). Strachan et al. (2009) concluded that due diligence is required by all adult leaders to create a positive environment through the integration of family, school, and community to produce healthy and competent young citizens through the use of sport.

\section{Appropriate Sport Specialization}

The continuation of early sport specialization is inevitable, regardless of the risks involved, empirical disadvantages, and avoiding advice. Therefore, it is important to discuss the appropriate and safe practice of sport specialization. A primary concern related to early sport specialization is the proper age that a young athlete should even consider the idea. DiFiori et al. (2014) stressed that chronological age is not a good indicator to base this decision upon due to different rates of motor, cognitive, and social skill development, independent of age. Gould (2010) reported a study on swimmers who specialized at a later age advanced at a greater rate than those who specialized at an early age. Gould (2010) suggested that coaches and parents should take a conservative approach encouraging multiple sport involvement prior to 14-15 years of age at which time sport specialization can be considered. Ferguson and Stern (2014) offered the idea that different sports have unique inherent demands, risks, and cultures. Therefore, when considering an appropriate age to consider specialization, it is critical to look at each sport differently regarding talent recognition, peak performance, and career length. Strachan, Cote, and Deakin (2009) noted that early specialization begins with an investment period, around age 8 , in which a high volume of deliberate practice occurs in one specific activity with intent to achieve excellence rather than just playing for fun.

\section{Practical Application of Sport Specialization}

Positives exist for early sport specialization and multi-sport involvement; however, the risk associated with early specialization do not out-weigh the rewards. Parents, players, and coaches need to conduct a realistic analysis of the ultimate goal of youth sports by assessing the percentage of elite athlete status achievement, the negative physical and mental side-effects, and the long-term health risks that are connected to early specialization. Ferguson and Stern (2014) concluded that sport specialization might be necessary for those in search of becoming an elite athlete, yet appropriate timing and training is vital for long-term success. A child's desire to become the next Tiger Woods is a naive, unrealistic goal. Recognizing the marginal chance of obtaining elite status, yet still striving for excellence and acquiring knowledge to support a life of healthy physical activity is a more realistic perspective and goal. The following section will discuss why parents, players, and coaches should refrain from early sport specialization and focus on development and the goal of fitness for a lifetime. The physical development of an adolescent differs per individual. However, research shows the maturity of a human body is continuous through ages 14-15 (Sherar, Baxter-Jones, Faulkner, \& Russell, 2007). Therefore, from the perspective of training an athlete properly, multiple dimension development should be the focus through at least age 15. Early specialization prior to maturation may increase the risk of overuse injury. Whereas, proper training in the early years will prepare the body to withstand specialized activity as the body matures. Proper mental development of a child is of equal importance to physical development. Early sport specialization often interferes with the mental capacity to not only play a sport but advance intellectually. Schooling plays a large role in specialization decision-making. Some athletes choose to learn at their own pace through home schooling or the evergrowing online educational environment. Thus, the quality of education may be sacrificed at the expense of sport participation. The social development to cooperate, interact, and learn from others has a major impact on the overall mental development of an adolescent. The development of an athlete's ability to handle stress while balancing life and sport cultivates a healthy mental state that can aid in burnout prevention (Martindale et al., 2005). An individual must develop a healthy mental mindset to be able to handle the pressures of competing at a high level throughout the calendar years.

\subsection{Practical Application of Sport Specialization from a Parent's Perspective}

Youth sports are big business and come at a steep price. Yet, some parents view year-round sport participation at an early age from an investment perspective. According to Sullivan (2015), early sport specialization often has a significant economic impact on the parents' budget with some parents spending up to $10 \%$ of their income on select/club sports in one season. Select/club sport fees include team expenses, travel, facilities, uniforms, equipment, insurance, and tournament costs ranging from $\$ 2,000$ to $\$ 15,000$ per year. This cost rarely includes the cost associated 
with the family to travel to watch their child compete. Travel costs include lost days from work, hotel, food, and admission fees. Youth coaches sell their services by telling parents that participation in elite select/club sport leagues significantly increase the child's potential to be seen by college recruiters. From a financial perspective, parents are willing to pay the price in order for their child to have a chance to receive an athletic scholarship and play ball at the college level. Although parents attempt to justify these expenditures, the reality is that this same money could have been invested in a savings account thereby guaranteeing a college education. Specialization in sport may also have a direct impact on family dynamics. Participation in a select/club league requires a significant time commitment for the child and at least one of the parents. The parent must coordinate travel to/from practices and games as well as make time for homework, meal prep, and adequate sleep. The time spent on the road and at the ball field results in time away from the family. Parents must find a way to incorporate dedicated quality family time in order to maintain strong family unity. For families with more than one child, the stress to 'divide and conquer' often has a negative impact on the parents as well as the children. Parents are forced to focus on only one child while the spouse assumes parental duties with the other children. Coordinating practice and game schedules, basic household chores, and work schedules become the daily norm. The negative impact of sport specialization can breakdown a family structure.

\section{Conclusion}

Acknowledging that regardless of the risks and negative attributes associated with early sport specialization, parents and coaches will continue to pressure kids and young teens to focus on a single sport in pursuit of achieving professional athlete status. Through the examination of early sport specialization, it is evident that the end goal must be retained in the decision-making processes - what is the purpose of specialization? Skill development needs to be viewed through a lens that considers elements such as periodization, strength and power development, transfer skills, and overall health of the individual. Sport specialization may be appropriate in unique situations but only after the development of specific skills, abilities, and psychological maturity. As sport professionals, parents and coaches should be educated the pros/cons of early sport specialization. Ultimately, the focus on sport participation should be to increase physical activity, psychological development, and appreciation for a lifetime.

\section{References}

Bailey, R., Collins, D., Ford, P., MacNamara, A., Toms, M., \& Pearce, G. (2010). Participant development in sport: An academic review. Sports Coach UK, 4, 1-134.

Baker, J., Cote, J., \& Abernethy, B. (2010). Sport-specific practice and the development of expert decision-making in team ball sports. Journal of Applied Sport Psychology, 15(1), 12-25.

Callahan, T. (2010). His father's son: Earl and Tiger Woods. New York, NY: Penguin Group.

DiFiori, J. P., Benjamin, H. J., Brenner, J. S., Gregory, A., Jayanthi, N., Landry, G. L., \& Luke, A. (2014). Overuse injuries and burnout in youth sports: A position statement from the American Medical Society for Sports Medicine. British Journal of Sports Medicine, 48(4), 287-288.

Ericsson, K. A., Krampe, R. T., \& Tesch-Römer, C. (1993). The role of deliberate practice in the acquisition of expert performance. Psychological Review, 100(3), 363.

Ferguson, B., \& Stern, P. J. (2014). A case of early sports specialization in an adolescent athlete. The Journal of the Canadian Chiropractic Association, 58(4), 377.

Haff, G. G., \& Triplett, N. T. (2015). Essentials of Strength Training and Conditioning (4th ed.). Champaign, IL: Human Kinetics.

Korman, C. (2015, April 15). AAU basketball has a lot of problems but it's still the best way to develop young players. USA Today. Retrieved from http://ftw.usatoday.com/2015/04/aau-basketball-scandals

Martindale, R. J., Collins, D., \& Daubney, J. (2005). Talent development: A guide for practice and research within sport. Quest, 57(4), 353-375.

McLeod, T. C. V., Decoster, L. C., Loud, K. J., Micheli, L. J., Parker, J. T., Sandrey, M. A., \& White, C. (2011). National Athletic Trainers' Association position statement: Prevention of pediatric overuse injuries. Journal of Athletic Training, 46(2), 206.

Merkel, D. L. (2013). Youth sport: Positive and negative impact on young athletes. Journal of Sports Medicine, 4, 151160.

Myer, G.D., Jayanthi, N., Difiori, J.P., Faigenbaum, A.D., Kiefer, A.W., Logerstedt, D., \& Micheli, L.J. (2015). Sport specialization, part 1: Does early sport specialization increase negative outcomes and reduce the opportunity for success in young athletes? Sports Health, 7(5): 437-442.

Russell, W. D., \& Limle, A. N. (2013). The relationship between youth sport specialization and involvement in sport and physical activity in young adulthood. Journal of Sport Behavior, 36(1), 82.

Sherar, L. B., Baxter-Jones, A. D., Faulkner, R. A., \& Russell, K. W. (2007). Do physical maturity and birth date predict talent in male youth ice hockey players? Journal of Sports Sciences, 25(8), 879-886.

Strachan, L., Côté, J., \& Deakin, J. (2009). "Specializers" versus" samplers" in youth sport: Comparing experiences and outcomes. Sport Psychologist, 23(1), 77. 
Sullivan, P. (2015, January 16). The rising costs of youth sports in money and emotion. New York Times. Retrieved from https://www.nytimes.com/2015/01/17/your-money/rising-costs-of-youth-sports.html?_r=0

Thompson, P. D., Arena, R., Riebe, D., \& Pescatello, L. S. (2013). ACSM's new preparticipation health screening recommendations from ACSM's guidelines for exercise testing and prescription. Current Sports Medicine Reports, $12(4), 215-217$.

Wiersma, L. D. (2000). Risks and benefits of youth sport specialization: Perspectives and recommendations. Pediatric Exercise Science, 12(1), 13-22. 